\title{
Cartas cristãs como mídia comunitária: o que Paulo de Tarso pode ensinar sobre comunicação popular?
}

\author{
Christian letters as community media: what Paul of Tarsus can teach about \\ popular communication?
}

\begin{abstract}
Sérgio Luiz Gadini
Doutor em Ciências da Comunicação pela Universidade do Vale do Rio dos Sinos (Unisinos), mestre em Comunicação e Cultura Contemporâneas pela Universidade Federal da Bahia (UFBA) e jornalista pela Universidade Federal de Santa Maria (UFSM). Coordenador do Programa de Pós-Graduação (mestrado) em Jornalismo da Universidade Estadual de Ponta Grossa (UEPG). <sergiogadini@yahoo.com.br.>
\end{abstract}

\section{Kevin Willian Kossar Furtado}

Mestre em Ciências Sociais Aplicadas e bacharel em Comunicação Social/Jornalismo pela Universidade Estadual de Ponta Grossa (UEPG). Professor substituto no Departamento de Jornalismo da UEPG. Editor gerente da Revista Brasileira de Ensino de Jornalismo.

<kevin@aol.com.br>

\section{RESUMO}

É possível indicar aspectos de mídia comunitária nas cartas cristãs do apóstolo Paulo de Tarso? Quais elementos possibilitam compreender e discutir alguma perspectiva de interesse coletivo e comunitário nas epístolas que ganharam o mundo, mais de 20 séculos depois de elaboradas? Este é o objetivo reflexivo do presente texto. Para isso, além dos conceitos de comunicação comunitária, e uma contextualização do cenário em que as cartas paulinas foram produzidas e divulgadas, o texto trabalha com as referências conceituais do Jornalismo apresentadas por Peucer (2004) e Groth (1966). Para além de uma agenda de temas voltados aos interesses dos grupos com que dialogava, as cartas do apóstolo cristão desempenhavam um papel pedagógico e reflexivo para as respectivas comunidades a que os escritos eram dirigidos. Elementos revelam que o hábito de enviar cartas, deste modo, também ajudava concretamente na função - militante, religiosa e comunitária - do apóstolo. O debate conceitual aqui apresentado não visa qualquer apologia dogmática/ proselitista, mas antes uma reflexão associativa com uma das marcas tradicionais do Jornalismo: o interesse coletivo, sempre buscado nas produções editoriais, sejam estas para qual segmento ou grupo social a que são destinadas.

Palavras-chave: Mídia comunitária. Cartas cristãs. Teorias do Jornalismo.

\section{ABSTRACT}

Is can indicate aspects of community media in Christian letters of the apostle Paul of Tarsus? What elements make it possible to understand and discuss some prospect of collective and community interest in the epistles that won the world, more than 20 centuries after elaborate? This is reflective objective of this text. For this, in addition to community communication concepts, and contextualizing scenario in which the pauline letters were produced and disseminated, the text works with the conceptual references of Journalism presented by Tobias Peucer (2004) and Otto Groth (1966). Beyond to an agenda of themes focused to the interests of groups that dialogued, the letters of the Christian apostle played a pedagogical and reflective role to their communities that the writings were directed. Elements show that the habit of sending letters, thereby, also helping specifically in the function - militant, religious and community - the apostle. The conceptual discussion presented here is not intended to any dogmatic apology dogmatic/ proselytist, but rather a reflection associative with one of the traditional brands of Journalism: the collective interest, always sought in the editorial productions, are those for which segment or social group to which they are intended.

Keywords: Community media. Christian letters. Theories of Journalism. 


\section{Apontamentos introdutórios entre Jornalismo, cartas bíblicas e mídia comunitária}

\section{O Jornalismo a partir de Tobias Peucer}

O alemão Peucer (2004) foi o defensor da primeira tese em Filosofia do Jornalismo apresentada em uma instituição de ensino superior de que se tem registro, feito realizado em 1690, na Universidade de Leipzig, Alemanha. 'De relationibus novellis' traça, em 29 parágrafos, uma comparação entre o Jornalismo e a História.

Um trabalho sistematizado e exposto há mais de 300 anos mostra que as noções que ora definem o Jornalismo e suas práticas não se constitui de uma invenção moderna, do pós-Revolução Industrial e pós-lluminismo, mas como resultado de uma atuação profissional (e, em alguns casos - sobremaneira vistos na Idade Média, por conta da censura prévia -, amadora e clandestina) que acompanha a história humana há pelo menos 2.000 anos, contando do tempo das Actas Urbanas do Império Romano, mesmo que essa logicamente, não possua os mesmos contornos do que hoje se concebe como jornalismo.

Paulo da Rocha Dias, tradutor e escritor do preâmbulo da tese de Peucer, fala que a mesma apresenta os tipos de relatos usados como forma de comunicação desde a antiguidade pela cultura ocidental e identifica o jornalismo conforme a perspectiva do singular. Debate as noções de autoria, noticiabilidade, verdade e credibilidade. Aponta critérios de seleção dos relatos e restrições aos conteúdos que devem, ou não, ser utilizados. $O$ apresentador da referida obra também apresenta as formas e estilos dos periódicos da época (Peucer, 2004).

Dias conta que Peucer fez parte de um grupo que começou a pesquisar e publicar os resultados de suas investigações nas universidades alemães na metade do século XVII. Naquele contexto, a Alemanha situavase como tradicional e proeminente nos estudos e pesquisas em Jornalismo, posteriormente impulsionada por notáveis pesquisadores como Otto Groth e Max Weber. Por conta dessa tradição alemã, em Leipzig surge o Leipzig Zeitung4, primeiro diário impresso da história (Peucer, 2004).

No preâmbulo da tradução da tese, Paulo Dias assegura que os conceitos encontrados na obra - e investigados de maneira científica por Peucer -, são familiares à maioria dos temas sistematizados e recorrentes na maioria das atuais pesquisas da área. 


\section{O Jornalismo a partir de Otto Groth}

No presente trabalho, as referências da obra de Otto Groth foram retiradas da apresentação do trabalho do alemão feitas por Faus Belau (1966) para uma versão espanhola. Faus Belau observa que seu trabalho se constitui como um resumo da ciência jornalística de Otto Groth, indicando que "muchas de las modernas teorías sobre Periodismo e Información que hoy circulan, tienen su base en la obra del Dr. Groth, aún cuando los creadores de las mismas no le mencionem muchas veces en sus bibliografias"1 (Faus Belau, 1966, p. 16).

Tal referência implica que existem no Jornalismocaracterísticas conceituais e estruturais básicas que definem o campo, e que já eram praticadas, mesmo que inconscientemente, em momentos históricos distantes da humanidade, sem que tivessem sido sistematizadas. Ao seu modo, Peucer, há pouco mais de 300 anos, aglutinava em sua tese os usos informativos e 'periodísticos' que se estruturavam como fazeres que hoje se pode chamar de jornalísticos. Groth também se preocupou em sistematizar as principais características que definem o Jornalismo, visto que pretendia alcançar o reconhecimento de uma "Ciencia Periodística ${ }^{2 "}$ como ciência cultural independente, o que, até a publicação de sua obra, era negado (Faus Belau, 1966, p. 16). Ao citar autores contemporâneos do Jornalismo, enfatizam-se aqui os pressupostos dos teóricos alemães, explicitando suas influências e relevância dos trabalhos aos estudos atuais da área.

Para uma delimitação metodológica, vale ressaltar que Groth usava o termo "Periodik" para se referir à imprensa, em geral, envolvendo jornais impressos e revistas, os principais objetos de estudo na época (Faus Belau, 1966).

\section{As cartas bíblicas de Paulo de Tarso em perspectivas de interesse comunitário}

Sobre a origem de Paulo, Porter (2009, p. 226) escreve que no livro de Atos (Novo Testamento), o apóstolo afirma ser nativo de Tarso, judeu e fariseu por nascimento, e discípulo do rabino Gamaliel, em Jerusalém. Paulo declara nas cartas que foi circuncidado, que pertencia à tribo de Benjamim e que foi criado

1 "muitas das modernas teorias sobre Jornalismo e Informação que circulam hoje têm suas bases na obra de Dr. Groth - ainda que os criadores dessas teorias, muitas vezes, não o mencionem em suas bibliografias" (Faus Belau, 1966, p. 16). No presente trabalho, as traduções do texto de Angel Faus Belau foram retirados da tradução para o português feita por Felipe Simão Pontes e Melina de la Barrera Ayres. 2 "Ciência Jornalística" na tradução de Felipe Simão Pontes e Melina de la Barrera Ayres, termo que será usado ao longo do trabalho juntamente com "Ciencia Periodística". 
como fariseu (Fp 3:5). Os textos de Paulo, ressalta Porter, mostrariam assim uma "familiaridade com os pontos de vista e métodos do judaísmo rabínico do século I da Era Cristã".

A cidade de Tarso foi descrita por Paulo como "não mediana". Porter (2009) informa que ela era a próspera capital da província romana da Cilícia, conhecida pela produção de tendas, o que, em certa medida, explica a ocupação profissional de Paulo (At 1:8). Tarso era também um centro intelectual, o que pode explicar as influências helenísticas observadas em fragmentos de seus textos e a familiaridade do apóstolo, ainda que rasa, com as doutrinas populares dos estóicos e cínicos. Sobre a cidade de nascimento de Paulo, Tarso, o geógrafo Strabo, escrevendo por volta dos primeiros anos do primeiro século d.C., relata Bruce, descreve a população local como ávida por atividades culturais, e que se aplicava ao estudo da filosofia, das artes e de todo aprendizado em geral, a "enciclopédia", de tal modo que Tarso parecia superar, nesses aspectos, as cidades de Atenas e Alexandria, e podia ser"considerada uma espécie de cidade universitária", friza o geógrafo (Bruce, 2003, p. 20). Pelas projeções de estudiosos da época, estima-se que Paulo nasceu em Tarso, provavelmente, na primeira década da Era Cristã.

Da tribo de Benjamim, como mesmo relata em Romanos 11:1, Paulo transparece a descrição de Bruce: nasceu numa família judaica com direitos de cidadania romana, em uma cidade de fala grega, mas que usava o aramaico nas conversações domésticas e também na sinagoga que frequentava. $A$ família de Paulo, complementa o autor, mantinha o "estilo de vida judeu e conservava vínculos com o país natal". Todavia, o apóstolo deve ter tido poucas oportunidades de usufruir da cultura de Tarso na adolescência, já que passou essa fase da vida em Jerusalém para receber uma educação ortodoxa judaica (2003, p. 39).

Em síntese, conforme a descrição que se encontra em Atos 22:3, Paulo era judeu, nascido em Tarso da Cilícia (educado em Jerusalém) e instruído por Gamaliel, o principal fariseu da época, segundo os preceitos da lei dos judeus, e era zeloso para com Deus. Paulo se dizia fariseu, no que diz respeito à lei (Fp 3:5), a seita mais severa do judaísmo no período. Paulo falava grego e também tinha o privilégio de haver nascido cidadão romano e ter nome latino, além do hebraico Saulo. "Não se sabe como sua família obteve essa cidadania, mas a criação nos Atos do status e do privilégio que ela concedia está de acordo com a prática legal romana no século I" (Porter, 2009). O teólogo Charles Swindoll destaca a proeminência do apóstolo. "Não conheço mais ninguém na Bíblia, exceto o 
próprio Cristo, que tivesse influência mais profunda em sua época e na nossa do que Paulo" (2003, p. 10).

Giuseppe Barbaglio avalia as cartas do Novo Testamento como a grande herança espiritual de Paulo de Tarso. E, ao contrário do que diz o senso comum religioso, não concebe o apóstolo como um intelectual, ou um pensador, num estilo clássico, mas como um 'homem de ação'. Essa variável, todavia, não rebaixa a importância de Paulo, e indica uma outra contribuição social, orgânica, se pensar no conceito de Antonio Gramsci³.

Para Barbaglio, Paulo elaborou uma profunda interpretação da fé cristã e foi um incansável propagador do evangelho, além de estar "sempre alerta aos problemas de suas comunidades" da Ásia e da Europa (1989, p. 21).

Como se vê, não se trata de vislumbrar um intelectual no sentido teórico (ou filosófico da expressão), mas um homem de ação. A atuação de Paulo se assemelha ao do jornalista, um indivíduo que age em conformidade e em sintonia com as demandas e problemas da comunidade de onde fala, escreve, publiciza e, muitas vezes, também atua. Uma ação com um duplo percurso: tanto voltado aos limites dos grupos para uma audiência maior, como do retorno das cobranças de pautas locais, em geral almejadas em atitudes concretas no cotidiano dos responsáveis por levantar tais temas. Todo esse movimento pressupõe o conhecimento pleno do local por parte do jornalista.

Durante maior parte da vida, revela Bruce, Paulo esteve exposto ao modo de vida grego. Assim como Barbaglio, Bruce parece não ver o apóstolo apenas como um intelectual, que pensaria o mundo à distância da vida da comunidade. "O conhecimento da literatura e do pensamento grego que suas cartas evidenciam faziam parte do conhecimento comum das pessoas instruídas no mundo helenista da época; ele não indica uma instrução formal recebida de professores gregos" (Bruce, 2003, p. 121). Pode-se encontrar, em fragmentos dos textos de Paulo, conceitos e expressões oriundos do estoicismo popular, colocadas na defesa de contextos cristãos. Bruce (2003, p. 122) observa que, mesmo pregando o evangelho aos helenos, Paulo não o fazia de modo 'helenizado'.

Bruce também considera Paulo como um homem de ação, eapresenta duas razões para tanto: o apóstolo colaborou para que - pouco mais de uma geração após a morte de seu fundador - o cristianismo passasse de movimento dentro da comunidade judaica, de judeus para judeus, em uma religião considerada

3 A referência, aqui, é o conceito de intelectual orgânico, defendida por Antonio Gramsci, entre outras obras, em "Os intelectuais e a organização da cultura". Livro publicado no Brasil pela Editora Civilização Brasileira (1982). 
pelas autoridades do Império Romano como predominantemente gentia. É, aliás, esta conexão que teria processado uma espécie de 'antítese de judeu/ cristão, onde antes se demarcava um conflito judeu/gentio. Na mesma lógica, por escrever seus textos em grego, mesmo com o surgimento do cristianismo ter se dado no sudoeste da Ásia, cuja língua usual era o aramaico, em tempos de comunicação com forte caráter oral, pode-se afirmar que Paulo propiciou que seus escritos se mantenham presentes nas sociedades contemporâneas, quase 20 séculos após a divulgação de suas versões preliminares e manuscritas.

Cabe ao comunicador, em certos contextos, materializar suas produções, buscando condições para que tais expressões circulem. Mesmo com os indicadores de que o acesso aos meios de comunicação - sobretudo a internet - tenha crescido desde o final dos anos 1990, o contingente atingido pela comunicação comunitária, que se localiza, predominantemente, nas periferias das médias e grandes cidades, longe dos espaços estruturais de informação e poder, cobra por estratégias diferenciadas para que a comunicação seja acessada por um maior número de pessoas. Caberia, por exemplo, imprimir textos sobre o local e disponibilizá-los em pontos centrais das comunidades ou através da distribuição para agentes de referência que, por contatos e em cadeia, ampliaram o alcance de tais produtos jornalísticos.

Paulo não era um teólogo sistemático. Talvez, um pouco diferente, se preocupou com as situações concretas das igrejas, e buscou resolver os dilemas que surgiam entre ele e seus interlocutores de maneira teologicamente fundamentada. "Em poucas palavras, sua teologia poderia ser definida como uma teologia aplicada" (Conzelmann, 1969, p. 22 apud Barbaglio, 1989, p. 47).

Assim, cabe ao comunicador social, e talvez mais ainda aos colaboradores de mídia comunitária, identificar o que há de mais peculiar e concreto nos problemas registrados nos mais diversos espaços coletivos, possibilitando expressões e condições de cobrança aos gestores sociais, através da publicização de produtos que abordam temas e demandas comunitárias.

\section{Cartas paulinas como elemento agregador de comunidades religiosas}

As cartas (epístolas) formam uma parte do Novo Testamento da Bíblia. E, como lembram Miller e Huber (2006, p. 70), "se eliminássemos as cartas do Novo Testamento, perderíamos 21 dos 27 livros". Dessas, 13 - e, para alguns, 14 (Hebreus) -, quase a metade dos livros do Novo Testamento, são atribuídas a Paulo, apesar da autenticidade da autoria não registrar garantias históricas documentais (Miller; Huber, 2006, p. 69). Os autores consideram as cartas de 
Paulo como os "livros mais antigos do Novo Testamento" - escritos, inclusive, antes mesmo de que as histórias de Jesus Cristo fossem sistematizadas pelos discípulos.

Para a tradição, apresenta Barbaglio, 14 cartas compreendem a obra epistolar de Paulo: Romanos, 1 e 2 Coríntios, Gálatas, Efésios, Filipenses, Colossenses, 1 e 2 Tessalonicenses, 1 e 2 Timóteo, Tito, Filemon e Hebreus. 0 mesmo autor defende que a pesquisa histórico-crítica (consolidada a partir do século XIX) já verifica essa mesma referência. Algumas conclusões de estudos da área são reconhecidas em diferentes países do mundo, enquanto outras permanecem como objeto de construção. A epístola de Hebreus, por exemplo, pode não ter sido escrita por Paulo; as cartas pastorais (1 e 2 Timóteo, Tito), dirigidas a uma única pessoa, são tardias, e atribuídas à escola dos discípulos do apóstolo. E, discute-se ainda a autenticidade da carta aos Efésios. Conforme Barbaglio, críticos e analistas bíblicos questionam a autoria paulina das cartas aos Colossenses e a 2 Tessalonicenses, enquanto outros pesquisadores aceitam a última como do apóstolo. Assim, atribui-se a Paulo, consensualmente, sete cartas: Romanos, 1 e 2 Coríntios, Gálatas, Filipenses, 1 Tessalonicenses e Filemon (Barbaglio, 1989, p. 45).

Bruce classifica as epístolas paulinas como a principal fonte de informação sobre a vida e obra do apóstolo. E, ao mesmo tempo, como fonte primordial de conhecimento dos primórdios do cristianismo, até por serem os documentos cristãos datáveis mais antigos, escritos entre 18 e 30 anos após a morte de Jesus. O mesmo autor elenca o Atos como principal fonte secundária da vida e obra de Paulo (Bruce, 2003).

O uso de cartas se configurava como uma estratégia de Paulo que, ao invés de voltar correndo para uma igreja quando ocorria algum problema, pois em certos casos estava fisicamente a centenas de quilômetros do local, escrevia cartas com as orientações necessárias aos seus correligionários (Miller; Huber, 2006). E, aqui, é necessário observar que, na época de Paulo, e por diversos séculos seguintes, filósofos, líderes religiosos, dirigentes militares e outros pensadores usavam cartas como uma ferramenta para espalhar os seus ensinos para uma ampla audiência. As cartas com esses propósitos ficaram conhecidas como epístolas, da palavra grega comum para "carta", explicam Miller e Huber (2006, p. 70).

O hábito de enviar cartas, deste modo, também ajudava concretamente na função - militante, religiosa e comunitária - do apóstolo. Por conta de suas constantes viagens, com o intuito de fundar igrejas em diferentes locais do Império Romano; as epístolas o ajudavam a ministrar para mais de uma cidade 
ao mesmo tempo. Enquanto pregava em uma localidade, escrevia para líderes e colegas de congregações distantes, "geralmente com a intenção de que suas cartas fossem lidas em voz alta durante as cerimônias de adoração e [...] que circulassem em outras igrejas" (Miller; Huber, 2006, p. 70).

Em outros termos, ao seu modo e contexto, Paulo adota o melhor suporte disponível para que a comunicação pudesse alcançar uma extensa e mais eficaz audiência. Aqui o senso comunitário se apresenta no desejo de Paulo de que as cartas fossem lidas em público durante os cultos, ajuntamento que reunia o maior número de membros da comunidade e que fossem espalhadas em outras igrejas. As cartas continham inúmeros relatos - alguns exemplificados adiante - do que ocorria em outras comunidades cristãs, o que criava e mantinha um espírito de pertencimento e de unidade entre os pioneiros do cristianismo.

Os mensageiros que entregavam as epístolas de Paulo entre os povoados geralmente permaneciam algum tempo com pessoas das respectivas comunidades, ajudando-as a executar os conselhos do apóstolo e, muitas vezes, traziam respostas e outras notícias de volta ao remetente (Porter, 2009; Miller, 2006; Huber 2006). E, pois, de modo pragmático, por mais que a função do comunicador não seja resolver os problemas das comunidades, identifica-se na figura do agente comunicacional uma possibilidade de ver suas demandas sanadas, pois este dialoga, por meio da publicização jornalística, com os centros decisórios que podem interferir na vida dos grupos em discussão. $A$ comunicação popular exige a disponibilidade de tempo para situar os membros de uma comunidade, através do trabalho jornalístico, sobre seus direitos enquanto espaço inserido em uma área geográfica sob jurisdição de um ente governamental.

Por mais que 21 livros do Novo Testamento sejam considerados epístolas literárias, ressalva Porter, nem todos possuem o mesmo gênero, demonstrando os diferentes tipos de cartas comuns à época. Existem as pessoais, chamadas pastorais; e as cartas formais, pensadas para uma audiência maior, como uma igreja ou comunidade, que tratam de temas amplos e remetem conselhos e instruções. Na avaliação de Porter, as cartas de Paulo reuniam aspectos formais e mais pessoais, e eram destinadas a serem lidas no culto público (2009, p. 239).

Segundo Porter, admite-se que a primeira carta escrita pelo apóstolo é a de I Tessalonicenses, destinada à igreja de Tessalônica, atual Salônica, localizada no norte da Grécia. Foi escrita, provavelmente, na cidade de Corinto, em 50 d.C. A cidade foi visitada durante a segunda viagem missionária de Paulo, descrita em Atos 16-18. A pregação na sinagoga local resultou num considerável número de convertidos. Todavia, a oposição das autoridades judaicas forçou Paulo a deixar 
a cidade (At 17:1-9). A Carta aos Tessalonicenses, por exemplo, "faz um retrato interessante da comunidade cristã num estágio inicial", afirma Porter (2009, p. 242).

Escritas em Éfeso por volta de 55 d.C., durante a segunda viagem missionária de Paulo, as cartas aos coríntios possuem alguns problemas literários, discute Porter, principalmente a segunda, a qual, em tese, foi formulada de missivas enviadas em diferentes momentos. Não obstante, a epístola apresenta "vivamente" os problemas e debates que enfrentava uma jovem igreja de uma cidade cosmopolita. "Mais do que qualquer texto de Paulo, as duas cartas à igreja coríntia fornecem o quadro vivido de uma congregação cristã primitiva" (Porter, 2009, p. 243).

Desde modo, os usos missivistas de Paulo se encaixam na noção de Brignol (2010, p. 123), a qual relata que, historicamente, a carta foi usada como meio de comunicação de migrantes, e que essa estratégia "faz pensar sobre uma interculturalidade que se constrói não apenas pelos fluxos migratórios, mas muito através dos meios de comunicação".

\section{Factualidade, interesse coletivo e senso aglutinador das cartas}

Ao longo da história humana, as comunidades foram (e são) pensadas e abordadas em suas diferentes especificidades. Esta tônica permeia os exemplos dos textos paulinos encontrados relação às suas variadas disposições nas categorias jornalísticas teorizadas por Peucer e Groth e que seguem arroladas doravante.

No livro de Romanos, pensando o critério jornalístico da factualidade (Peucer, 2004, p. 15), pode-se encontrar tal característica na passagem do capítulo/verso 2:24, que diz, com relação a povo romano, que "'o nome de Deus é blasfemado entre os gentios por causa de vocês"'4 . Ao tratar da questão da culpa de judeus e gentios ${ }^{5}$ com relação ao julgamento humano, Paulo relata que os judeus residentes em Roma eram motivo de opróbrio perante as nações gentílicas, por conhecerem a lei de Deus, se gloriarem nela, serem instruídos e ensinarem a mesma a outros, mas, não obstante, ter uma conduta diferente da recomendada por ela.

Em 1 Coríntios, a factualidade e o interesse comunitário podem ser vistos nos capítulos/versos 1:11, 3:1-6, 5:1, 11:18-21, 15:3-8 e 15:29. Paulo lida com

4 Todas as citações bíblicas que aparecem no trabalho foram retiradas da Nova Versão Internacional (NVI).

5 Gentio, para os judeus, era considerado todo aquele que não fazia parte de Israel e sua descendência e, após, passou a indicar todo aquele que não pertencia ao mundo cristão; pagão. 
as divisões dos membros da igreja em Corinto. Trata também da imoralidade sexual, conforme os padrões judaico-cristãos. Os relatos factuais dessa epístola circulam, basicamente, entre esses dois temas, além de falar de um acontecimento insólito: a ressurreição e aparecimento de Cristo.

No texto de 1 Coríntios 1:11 Paulo fala "Meus irmãos, fui informado por alguns da casa de Cloe de que há divisões entre vocês". Em 1 Coríntios 11:18-21:

Em primeiro lugar, ouço que, quando vocês se reúnem como igreja, há divisões entre vocês, e até certo ponto eu o creio. Pois é necessário que haja divergências entre vocês, para que sejam conhecidos quais dentre vocês são aprovados. Quando vocês se reúnem, não é para comer a ceia do Senhor, porque cada um come sua própria ceia sem esperar pelos outros. Assim, enquanto um fica com fome, outro se embriaga.

Com relação à imoralidade, a notícia do capítulo cinco é (auto) explicativa: “por toda parte se ouve que há imoralidade entre vocês, imoralidade que não ocorre nem entre os pagãos, ao ponto de um de vocês possuir a mulher de seu pai".

No capítulo oitavo da segunda carta aos coríntios, o apóstolo noticia a assistência prestada pela igreja da Macedônia no trabalho de recolher donativos para os pobres da Judeia, funcionando, aqui, como um exemplo ilustrativo do propósito e estratégia agregadora de pessoas no espírito comunitário dos grupos que recebiam as comunicações de Paulo.

Agora, irmãos, queremos que vocês tomem conhecimento da graça que Deus concedeu às igrejas da Macedônia. No meio da mais severa tribulação, a grande alegria e a extrema pobreza deles transbordaram em rica generosidade. Pois dou testemunho de que eles deram tudo quanto podiam, e até além do que podiam. Por iniciativa própria eles nos suplicaram insistentemente o privilégio de participar da assistência aos santos. E não somente fizeram o que esperávamos, mas entregaram-se primeiramente a si mesmos ao Senhor e, depois, a nós, pela vontade de Deus. Assim, recomendamos a Tito que, assim como ele já havia começado, também completasse esse ato de graça da parte de vocês (2Co 8:1-6, NVI).

Em Gálatas, quatro fragmentos da epístola se encaixam na noção de factualidade proposta por Peucer e de interesse comunitário comum: 1:6-7, 1:13-24, 2:1-14 e 3:13-20.

Admiro-me de que vocês estejam abandonando tão rapidamente aquele que os chamou pela graça de Cristo, para seguirem outro evangelho que, na realidade, não é o evangelho. O que ocorre é 
que algumas pessoas os estão perturbando, querendo perverter o evangelho de Cristo (1:6-7, NVI).

A epístola aos Tessalonicenses inicia com a notícia de que eles haviam se tornado referência para outros crentes:

De fato, vocês se tornaram nossos imitadores e do Senhor, pois, apesar de muito sofrimento, receberam a palavra com alegria que vem do Espírito Santo. Assim, tornaram-se modelo para todos os crentes que estão na Macedônia e na Acaia. Porque, partindo de vocês, propagou-se a mensagem do Senhor na Macedônia e na Acaia. Não somente isso, mas também por toda parte tornou-se conhecida a fé que vocês têm em Deus. O resultado é que não temos necessidade de dizer mais nada sobre isso, pois eles mesmos relatam de que maneira vocês nos receberam, e como se voltaram para Deus, deixando os ídolos a fim de servir ao Deus vivo e verdadeiro (1Ts 1:69, NVI).

\section{Marcas de interesse coletivo nas cartas (noticiosas) de Paulo}

No parágrafo XI de sua tese, Peucer menciona que na produção dos relatos deve haver uma separação entre o que é relevante e o que é banal, culminando na publicação daquilo que seja de interesse público. Em suas cartas, Paulo transmitia aos recém-cristãos somente o que era essencial para a comunidade e a fé. Em cada epístola há um tema central sobre o qual Paulo discorre e, em alguns casos, discute os problemas religiosos do grupo a quem fala.

Em Romanos, um texto que exemplifica a postura de Paulo ao tratar de assuntos pertinentes à comunidade, está no capítulo/versos 15:14-15:

[...] estou convencido de que vocês estão cheios de bondade e plenamente instruídos, sendo capazes de aconselhar-se uns aos outros. A respeito de alguns assuntos, eu lhes escrevi com toda a franqueza, principalmente para fazê-los lembrar-se novamente deles, por causa da graça que Deus me deu.

Passando à primeira epístola aos Coríntios, a notícia que trata sobre um dos benefícios da salvação, é exposta no capítulo/verso 2:9. “Todavia, como está escrito: 'Olho nenhum viu, ouvido nenhum ouviu, mente nenhuma imaginou o que Deus preparou para aqueles que o amam'". Aqui, Paulo se refere à expectativa de outro mundo possível. $\mathrm{O}$ apóstolo também noticia na carta um acontecimento que era considerado crime entre os crentes: a imoralidade. Aqui, Paulo conta sobre o caso de um filho que "possuiu" a mulher do próprio pai 
(1Co 5:1). Sobre a espera de uma nova pátria, o discípulo de Cristo anuncia um fato de interesse de todos os cristãos que possuem entes queridos mortos, os acontecimentos que sobrevirão antes da chegada da segunda volta de Jesus à Terra.

"Eis que eu lhes digo um mistério: Nem todos dormiremos, mas todos seremos transformados, num momento, num abrir e fechar de olhos, ao som da última trombeta. Pois a trombeta soará, os mortos ressuscitarão incorruptíveis e nós seremos transformados" (1Co 15:51-52, NVI).

E, na segunda carta ao povo de Corinto, o apóstolo notifica-os de que não fará outra visita à região, visto que alguns se sentiam incomodados com sua presença:

Por isso resolvi não lhes fazer outra visita que causasse tristeza. Pois, se os entristeço, quem me alegrará senão vocês, a quem tenho entristecido? Escrevi como escrevi para que, quando eu for, não seja entristecido por aqueles que deveriam alegrar-me. Estava confiante em que todos vocês compartilhariam da minha alegria. Pois eu lhes escrevi com grande aflição e angústia de coração, e com muitas lágrimas, não para entristecê-los, mas para que soubessem como é profundo o meu amor por vocês (2Co 2:1-4, NVI).

Outro texto que se aproxima ao interesse público apresenta Paulo relatando seus conflitos e temores, o encontro com Tito, sua recepção às notícias recebidas pelo colega de ministério, a explicação das condições que o levaram a escrever uma carta anterior e seu trânsito em meio aos coríntios.

Concedam-nos lugar no coração de vocês. A ninguém prejudicamos, a ninguém causamos dano, a ninguém exploramos. Não digo isso para condená-los; já lhes disse que vocês estão em nosso coração para juntos morrermos ou vivermos. Tenho grande confiança em vocês, e de vocês tenho muito orgulho. Sinto-me bastante encorajado; minha alegria transborda em todas as tribulações (2Co 7:1-4, NVI).

Em Gálatas, o texto que se harmoniza com o interesse público trata dos desígnios da religião judaica, e de como a morte de Cristo influencia o cotidiano de seus seguidores (Gl 3:17-20). Na epístola dirigida aos Filipenses, dois assuntos são de interesse comum: a aprovação de Timóteo (o qual seria enviado à igreja, como também Epafrodito) como auxiliador de Paulo; e a notícia do recebimento dos donativos enviados pelos Filipenses a Paulo (Fp 4:15-18). 
Ao falar aos Tessalonicenses, duas notícias são de interesse de todos os membros da igreja local; a de que a comunidade havia se tornado referência para outros crentes (1Ts 1:6-9); e o relato dos acontecimentos precedentes à volta de Cristo que se sucedem tanto aos crentes mortos, como aos que ainda estiverem vivos quando do retorno de Jesus (1Ts 4:14-17).

A linguagem acessível de Paulo também pode ser identificada como uma característica presente nas cartas de Paulo de Tarso, e também uma marca tradicional do Jornalismo, que tenta dialogar, e ser compreendido, por diferentes segmentos do público.

No parágrafo XXII de sua tese, Peucer $(2004$, p.24) descreve a linguagem a ser empregada nos relatos e dá subsídios e exemplos que demonstram o caráter claro e conciso exigido dos textos. Combate as palavras de difícil compreensão, as confusões de ordem sintática e as gírias, para que a maioria assimile claramente o que é dito, e para que os eruditos sintam-se satisfeitos com a leitura.

Em seus escritos, Paulo deixa claro que o propósito era comunicar mensagens assimiláveis aos seus interlocutores, o que se relaciona com a característica de linguagem acessível, "uma das particularidades que dos formatos jornalísticos", conforme já discute Peucer (2004, p.24). A primeira carta aos Coríntios contém três exemplos dessa estratégia e esforço (editorial): “Pois Cristo não me enviou para batizar, mas para pregar o evangelho, não porém com palavras de sabedoria humana, para que a cruz de Cristo não seja esvaziada" (1Co 1:17, NVl).

No verso 18, o apóstolo destaca que a mensagem de Cristo é a mensagem da cruz, com Seu sacrifício, e que toda a sabedoria e intelectualidade humana é loucura. No capítulo posterior, vê-se:

Eu mesmo, irmãos, quando estive entre vocês, não fui com discurso eloquente, nem com muita sabedoria para Ihes proclamar o mistério de Deus. [...] Minha mensagem e minha pregação não consistiram de palavras persuasivas de sabedoria [...] (1Co 2:1,4, NVI).

Já no verso 20, do capítulo quatro, Paulo traduz a mensagem do Reino de Deus e seu significado para cotidiano, se constituindo de poder, e não de palavras: "o Reino de Deus não consiste de palavras, mas de poder". Ou seja, o cristianismo se configura em ação, testemunho. Os relatos do apóstolo durante as cartas são de fácil assimilação, pois têm origem familiar, por fazer parte das crenças judaicas (adotadas pela fé cristã) que eram conhecidas dos povos que viviam ao redor da nação israelita e que aos poucos foram direcionadas ao cristianismo. 
Estratégia segmentada, integração (pela periodicidade) e artifício agregador (na difusão)

No último parágrafo de sua tese, Peucer (2004) chama a atenção aos variados gêneros dos periódicos de sua época. Ele cita literários, os que garantiam aos leitores a veiculação de coisas singulares e que estampavam títulos curiosos, os de eventos cívicos e as publicações que se ocupavam de diversos gêneros. Peucer não faz uma análise pormenorizada desses tipos, mas apenas uma referência à existência dessas publicações, que se constituem em formas de jornalismo segmentado.

Paulo, de forma similar, direcionava suas cartas para segmentos, interesses de grupos, problemas e demandas de cada localidade. Em meio a todo conjunto de temas presente em cada epístola, sempre há uma matéria central, predominante; peculiar às comunidades, como também um tópico que define o texto. A Bíblia Thompson (2005) define quais eram os segmentos centrais de cada epístola. A de Romanos trata do plano da salvação e exortava acerca dos deveres cristãos (p. 1409); nas duas cartas aos Coríntios, os temas principais são a purificação da igreja de falsos conceitos e a defesa do apostolado de Paulo ante os coríntios (p. 1411); a carta aos Gálatas trata da justificação pela fé, dá advertências contra a reversão ao judaísmo e vindica o apostolado de Paulo; a aos Filipenses discorre sobre Jesus Cristo e seus ensinamentos e influência na igreja local (p. 1413); e a primeira carta aos Tessalonicenses traça recomendações, conselhos e exortações para a igreja local (p. 1415).

Por mais que o objetivo primordial da comunicação comunitária seja dar vasão às demandas específicas das comunidades, na maioria das vezes, sem expressão nos espaços hegemônicos, em suas cartas Paulo trata de temas que uniam, mesmo em suas particularidades, os diferentes grupos com quem dialogava; em específico, do início de uma nova dispensação em torno da pessoa de Jesus Cristo.

Groth considera a periodicidade como a mais notável característica dos jornais e revistas. Em sua definição, a periodicidade é "un concepto del tiempo de La forma del periodik" (Faus Belau, 1996, p. 48), onde o objeto volta-se a um ponto fixo de repetição, o qual é o homem. O conceito de periodicidade do alemão não considera necessária a igualdade da aparição, pois tal conota um sentido de regularidade. Tal sujeição à aparição fixa diminui, para Groth, a capacidade do jornal de seguir o ritmo acelerado da vida. "El periódico debe

6 Um conceito do tempo da forma do periodik. 
adaptarse a esta corriente de la vida, y esa libertad en sí, le da una apariencia de vida humana. La Periodicidad es, pues, RITMO DE VIDA" (Faus Belau, 1966, p. 48). A concepção de Groth de periodicidade não prevê a repetição insistente. O alemão pontua que a periodicidade está determinada pelas finalidades, necessidades e costumes humanos, e que essa medida varia de acordo com as condições sociais e culturais.

Mesmo não expressa em versículos das cartas, a periodicidade pode ser identificada por algumas marcas: Paulo usava do epistolário para se comunicar com as comunidades fundadas/visitadas/auxiliadas e, sempre, após sua saída, escrevia cartas com notícias, orientações, críticas, entre outras coisas; Paulo teve sua obra interrompida por conta da sua morte em 64 d.C. (Porter, 2009), o que indica que ele continuaria escrevendo cartas, não fosse seu óbito; e porque suas cartas foram, após sua morte, duplicadas, algumas fundidas, outras produzidas, pelo processo de pseudepigrafia (Wickenhauser, 1963, p. 34 apud Barbaglio, 1989, p. 46).

Groth classifica a difusão como a segunda propriedade de forma da Ciência Jornalística - a primeira é a de periodicidade -, em contraste à universalidade e a atualidade que, para ele, são características de conteúdo dos jornais. A difusão pressupõe acessibilidade irrestrita a todas as formas de comunicação efetuadas, de modo que ninguém seja excluído de receber o conteúdo. O teórico considera que a difusão estende-se a todos os lugares e a todas as classes sociais. Isso, todavia, não significa que todos acessam o conteúdo jornalístico. O número de leitores é determinado por circunstâncias: geográficas, políticas, populacionais, sociais, econômicas, entre outras. Esses fatores, e os constrangimentos de cada esfera, delimitam, direta ou indiretamente, a intensidade da difusão.

A característica da difusão é classificada por Groth como uma noção de formato. Os versículos/notícias de Paulo não se encaixem nessa categorização. Entretanto, alguns indícios, pontuados por Miller e Huber (2006, p. 70), e por Porter (2009, p. 239), indicam que as epístolas paulinas abrigavam em si esse elemento. Os primeiros relatam que o apóstolo escrevia para líderes e colegas de congregações distantes "geralmente com a intenção de que suas cartas fossem lidas em voz alta durante as cerimônias de adoração e [...] que circulassem em outras igrejas"; e completa Porter: "As [...] cartas de Paulo [...] se destinavam a ser lidas no culto público". Ou seja, os escritos paulinos não ficavam circunscritos

7 "O jornal deve adaptar-se a esta corrente da vida e essa liberdade em si lhe dá uma aparência de vida humana. A Periodicidade é, portanto, RITMO DE VIDA". 
àqueles que os recebiam, mas eram difundidos publicamente durante as reuniões públicas das igrejas, possibilitando o acesso a quem tivesse interesse.

Portanto, importava fazer a informação circular entre os grupos, na perspectiva de interesse e senso comunitário, isso porque tais cartas escritas e enviadas aos membros das comunidades cristãs, para além do caráter infoevangelizador, também desempenhavam um papel integrador das pessoas no espírito comunitário de tais povoados.

\section{Considerações finais (a um debate reflexivo, sempre atual)}

Ao longo do texto, buscou-se apresentar alguns elementos para entender a possível abordagem das cartas bíblicas de Paulo de Tarso em uma perspectiva de interesse coletivo e comunitário nas epístolas que ganharam o mundo, ainda que mais de 20 séculos depois de elaboradas.

$\mathrm{E}$, para isso, além de uma necessária contextualização do cenário em que as cartas paulinas foram produzidas e divulgadas, o texto dialoga com as referências conceituais de Jornalismo apresentadas por Peucer (2004) e Groth (1966), relacionando algumas características de produção editorial com ações de mídia comunitária. Pelo trajeto conceitual realizado, pode-se sugerir que, para além de uma agenda de temas voltados aos interesses dos grupos com que dialogava, as cartas do apóstolo cristão Paulo desempenhavam um papel pedagógico e reflexivo para as respectivas comunidades a que os escritos eram dirigidos.

E, por fim, vale observar que o debate conceitual aqui apresentado não visa qualquer apologia dogmático/proselitista, mas antes uma reflexão associativa com uma das marcas tradicionais do Jornalismo: o interesse coletivo, sempre buscado nas produções editoriais, sejam estas para qual segmento ou grupo social a que são destinadas.

Afinal, a partirdos diversoselementos-dimensão informativa, pedagógica, agregadora e interativa - pode-se pensar que algumas das características dos textos produzidos por Paulo de Tarso, em forma de carta, já exerciam aspectos comunitários que, guardadas as proporções, os variados produtos de mídia segmentada comunitária encontrados nas sociedades complexas da contemporaneidade buscam desempenhar para melhor atingir e envolver seus respectivos atores e interlocutores. Trata-se, pois, de uma reflexão necessária aos estudos de comunicação comunitária, não como conclusão fechada, mas como possibilidade e desafio para melhor vislumbrar contribuições de tais produções voltadas aos grupos e movimentos comunitários. 


\section{Referências}

BARBAGLIO, Giuseppe. As cartas de Paulo, I. São Paulo: Loyola, 1989. (Coleção bíblica Loyola, v. 4).

BÍBLIA de referência Thompson. Com versículos em cadeia temática. São Paulo: Vida, 2005.

BíBLIA Sagrada. Nova Versão Internacional. São Paulo: Vida, 2000.

BRIGNOL, Liliane Dutra. Migrações transnacionais e usos sociais da internet: identidades e cidadania na diáspora latino-americana. 2010, 404 f. Tese (Doutorado em Ciências da Comunicação) - Programa de Pós-Graduação em Ciências da Comunicação, Universidade do Vale do Rio dos Sinos, São Leopoldo, 2010.

BRUCE, Frederick F. Paulo: o apóstolo da graça, sua vida, cartas e teologia. São Paulo: Shedd Publicações, 2003.

FAUS BELAU, Angel. A ciência jornalística de Otto Groth. Tradução de Felipe Simão Pontes e Melina de la Barrera Ayres. [Florianópolis]: [s. n.], [200-].

. La ciencia periodística de Otto Groth. Pamplona: Instituto de Periodismo de la Universidad de Navarra, 1966.

GRAMSCI, Antonio. Os intelectuais e a organização da cultura. Rio de Janeiro: Civilização Brasileira, 1982.

GROTH, Otto. $\mathbf{O}$ poder cultural desconhecido: fundamentos da Ciência dos Jornais. Tradução de Liriam Sponholz. Petrópolis: Vozes, 2011. (Coleção Clássicos da Comunicação Social).

KOSSAR FURTADO, Kevin Willian; GADINI, Sérgio Luiz. O jornalismo em forma de carta no primeiro século da Era Cristã: análise das epístolas bíblicas de São Paulo a partir das principais características jornalísticas. Estudos em Jornalismo e Mídia, Florianópolis, v. 10, n. 1, p. 183-204, jan./jun. 2013.

MILLER, Stephen M.; HUBER, Robert V. A bíblia e sua história. Barueri: Sociedade Bíblica do Brasil, 2006.

PEUCER, Tobias. Os relatos jornalísticos. Tradução de Paulo da Rocha Dias. Estudos em Jornalismo e Mídia, São Bernardo do Campo, v. 1, n. 2, p. 13-29, jul./dez. 2004. 
PORTER, J. R. A Bíblia - guia ilustrado das escrituras sagradas: história, literatura e religião. São Paulo: Publifolha, 2009. (Coleção referência).

SWINDOLL, Charles R. Paulo: um homem de coragem e graça. São Paulo: Mundo Cristão, 2003. (Série Heróis da Fé, v. 6).

Recebido em: 5/4/2015

Aceito em: 19/5/2015

Endereço dos autores:

Sérgio Luiz Gadini <sergiogadini@yahoo.com.br>

Rua Vidal de Negreiros, 927, ap 32 - Oficinas

CEP: 84040-060

Ponta Grossa/PR - Brasil

Kevin Willian Kossar Furtado <kevin@aol.com.br>

Rua Alfredo Pietrobelli, 535 - Boa Vista

CEP: 84072-090

Ponta Grossa/PR - Brasil 